\title{
Impact of Geography on Care Delivery and Survival for Noncurable Pancreatic Adenocarcinoma: A Population-Based Analysis
}

\author{
Elliott K. Yee, B.Arts Sc. 1,2; Natalie G. Coburn, MD, MPH2,3,4,5; Laura E. Davis, MSc; ; Alyson L. Mahar, PhD; \\ Victoria Zuk, MSc ${ }^{2}$; Vaibhav Gupta, MD, PhD ${ }^{2,4}$; Ying Liu, MSc ${ }^{4}$; Craig C. Earle, MD, MSc $c^{2,5,8}$; and Julie Hallet, MD, MSc ${ }^{2,3,4,5}$
}

\begin{abstract}
Background: Little is known about how the geographic distribution of cancer services may influence disparities in outcomes for noncurable pancreatic adenocarcinoma. We therefore examined the geographic distribution of outcomes for this disease in relation to distance to cancer centers. Methods: We conducted a retrospective populationbased analysis of adults in Ontario, Canada, diagnosed with noncurable pancreatic adenocarcinoma from 2004 through 2017 using linked administrative healthcare datasets. The exposure was distance from place of residence to the nearest cancer center providing medical oncology assessment and systemic therapy. Outcomes were medical oncology consultation, receipt of cancer-directed therapy, and overall survival. We examined the relationship between distance and outcomes using adjusted multivariable regression models. Results: Of 15,970 patients surviving a median of 3.3 months, $65.6 \%$ consulted medical oncology and $38.5 \%$ received systemic therapy. Regions with comparable outcomes were clustered throughout Ontario. Mapping revealed regional discordances between outcomes. Increasing distance (reference, $\leq 10 \mathrm{~km}$ ) was independently associated with lower likelihood of medical oncology consultation (relative risks [95\% $\mathrm{Cl}]$ for $11-50,51-100$, and $\geq 101 \mathrm{~km}$ were 0.90 [0.83-0.98], 0.78 [0.62-0.99], and 0.77 [0.55-1.08], respectively) and worse survival (hazard ratios [95\% Cl] for 11-50, 51-100, and $\geq 101 \mathrm{~km}$ were 1.08 [1.04-1.12], 1.17 [1.10-1.25], and 1.10 [1.02-1.18], respectively), but not with likelihood of receiving therapy. Receipt of therapy seems less sensitive to distance, suggesting that distance limits entry into the cancer care system via oncology consultation. Regional outcome discordances suggest inefficiencies within and protective factors outside of the cancer care system. Conclusions: These findings provide a basis for clinicians to optimize their practices for patients with noncurable pancreatic adenocarcinoma, for future studies investigating geographic barriers to care, and for regional interventions to improve access.
\end{abstract}

J Natl Compr Canc Netw 2020;18(12):1642-1650 doi: $10.6004 /$ jnccn.2020.7605

\footnotetext{
${ }^{1}$ Faculty of Medicine, University of Toronto, Toronto, Ontario; ${ }^{2}$ Cancer Program Evaluative Clinical Sciences, and ${ }^{3}$ Department of Surgery, Odette Cancer Centre Sunnybrook Health Sciences Centre, Toronto, Ontario; ${ }^{4}$ Department of Surgery, University of Toronto, Toronto, Ontario; ${ }^{5}$ ICES, Toronto, Ontario; ${ }^{6}$ Department of Epidemiology, Biostatistics and Occupational Health, McGill University, Montreal, Quebec; ${ }^{7}$ Department of Community Health Sciences, University of Manitoba, Winnipeg, Manitoba; and ${ }^{8}$ Division of Medical Oncology, Odette Cancer CentreSunnybrook Health Sciences Centre, Toronto, Ontario, Canada.
}

\section{Background}

Although rates of resection for pancreatic cancer have increased, $80 \%$ of patients still present with locally advanced unresectable or metastatic disease at diagnosis that is not amenable to curative intent treatment. ${ }^{1,2}$ Improving outcomes for the majority of patients with noncurable disease is therefore crucial.

Previous work has revealed underassessment and low treatment rates for pancreatic adenocarcinoma, with $35 \%$ of patients with advanced disease not seeing a medical oncologist and $62 \%$ not receiving systemic therapy. ${ }^{3-7}$ Multiagent systemic therapies can nevertheless improve survival and reduce symptom burden within this patient population. ${ }^{8-10}$ Therefore, a need exists to ensure that opportunities for treatment are adequate, if aligned with patients' wishes. To optimize access to and delivery of evidence-based care, and thereby improve outcomes for patients with pancreatic adenocarcinoma, an understanding of factors contributing to inconsistencies in assessment and treatment is necessary.

Geography is an important influencer of access to cancer care. ${ }^{11}$ Geographic location of treatment and the variable access it entails have been shown to impact the survival of patients with surgically treatable cancers. ${ }^{12-15}$ However, the relationships between location of cancer facilities, region of residence, access to care, and outcomes have rarely been examined in medical oncology care. In particular, this has not been assessed for the management of noncurable pancreatic adenocarcinoma.

Identifying the role of geography in care disparities may provide opportunities to address barriers to accessing care. We therefore sought to evaluate the geographic distribution of care delivery and its impact on

See JNCCN.org for supplemental online content. 
survival for patients diagnosed with pancreatic adenocarcinoma not undergoing curative-intent resection.

\section{Methods}

\section{Study Design and Setting}

We performed a population-based retrospective cohort study using linked administrative datasets at ICES (formerly known as the Institute for Clinical Evaluative Sciences) in Ontario, Canada. In 2016, Ontario's population of $13,448,494$ resided in a land area of $908,699 \mathrm{~km}^{2}$, with much of the population concentrated in the southern part of the province. ${ }^{16}$ The population under study receives universal, publicly funded healthcare through the Ontario Health Insurance Plan (OHIP) under the Canada Health Act. ${ }^{17}$ The present study was approved by the research ethics board of Sunnybrook Health Sciences Centre, and it is reported according to the RECORD statement. ${ }^{18}$

\section{Study Population and Cohort}

The study population comprised all patients with noncurable pancreatic adenocarcinoma, defined as unresected pancreatic adenocarcinoma, from January 1 , 2004, through October 31, 2017, as previously reported (supplemental eTable 1, available with this article at JNCCN.org). ${ }^{3,19}$

\section{Data Sources}

We linked administrative healthcare datasets at ICES using each patient's unique identification key number. Demographic and vital status data are stored in the Registered Persons Database (RPDB). ${ }^{20}$ The Ontario Cancer Registry (OCR) contains information about all patients diagnosed with cancer. ${ }^{21}$ Information about health services provided is contained within the National Ambulatory Care Reporting System, the Canadian Institute for Health Information Discharge Abstract Database and Same Day Surgery Database, ${ }^{22}$ the OHIP Claims Database, and the Cancer Activity Level Reporting database. Datasets are detailed in supplemental eTable 2.

The Postal Code Conversion File (PCCF) links postal codes to standard Ontario census geographic regions. ${ }^{23}$ Ontario contains 49 administrative geographic regions known as census divisions (CDs) (supplemental eFigure 1). ${ }^{24}$ Geospatial data pertaining to CDs were obtained from Statistics Canada as per the 2016 census. ${ }^{25}$ Cancer centers were identified from a list maintained by Cancer Care Ontario as sites providing systemic cancer treatment and classified into 4 levels of care. Level 1 centers are academic sites active in research and teaching; level 2 centers provide complex care with fewer academic responsibilities; level 3 centers are affiliate facilities; and level 4 centers are satellite facilities. Level 4 centers do not have medical oncologists onsite. ${ }^{26}$ Google Maps 3.35 (Alphabet Inc.) was used to generate the point location of each center with onsite medical oncology using latitude and longitude.

\section{Exposure}

The exposure of interest was distance to the nearest cancer center, defined as the straight-line distance in kilometers from the centroid of each patient's postal code to the nearest center with access to onsite medical oncology services (level 1, 2, or 3 centers). Distance to the nearest center was categorized as $\leq 10,11$ to 50,51 to 100 , or $\geq 101 \mathrm{~km}$, informed by the population distribution across the province. Straight-line distance has previously been used to measure geographic access to cancer care. ${ }^{15,27-33}$ Compared with regional measures of remoteness from care, such as rurality, direct distance measures access to care at the level of individual patients. ${ }^{34}$

\section{Outcomes}

Outcomes of interest were medical oncology consultation, use of cancer-directed therapy (CDT; chemotherapy and chemoradiation therapy), and median survival, as previously defined. ${ }^{3}$ Survival was measured from the date of diagnosis to the date of death of any cause. The end of follow-up was the date of either death or the end of the study, defined as March 31, 2018. This provided the opportunity for a minimum of 5 months of follow-up for all patients, representing median survival for this patient population..$^{4,19}$

\section{Covariates}

Variable definitions and data sources are detailed in supplemental eTable 1. Age and sex were abstracted from the RPDB, and year of diagnosis was abstracted from the OCR. Material deprivation quintile, an ecologic measure of material socioeconomic factors related to income, family structure, education, and housing, was assigned by postal code. ${ }^{35}$ The Elixhauser comorbidity index, comprising 30 comorbidities defined by ICD-9-CM codes, was used to determine comorbidity, with high comorbidity burden defined as Elixhauser index $\geq 4 .{ }^{36,37}$

\section{Statistical Analysis}

Supplemental eAppendix 1 details the statistical analysis. Descriptive analyses determined baseline characteristics of the cohort and outcomes, stratified by distance category and geographic region of residence.

Patients were linked to geographic regions using the PCCF. Choropleth maps of the primary outcomes across each geographic region visualized geographic trends, including each outcome's spatial distribution relative to cancer centers. ${ }^{27}$ Bivariate choropleth maps identified areas of overlap between medical oncology 
consultation and CDT receipt and between survival and the other primary outcomes, across geographic regions. This technique allows individual maps to simultaneously display 2 categorical variables and their spatial overlap using 2 distinct color gradients. ${ }^{38,39}$ All maps were produced using QGIS 2.12 (QGIS Geographic Information System; Open Source Geospatial Foundation Project).

Multivariable regression models examined the relationship between distance to the nearest cancer center (categorical) and each outcome. Relevant demographic and clinical characteristics were identified a priori as confounders to be adjusted for based on clinical relevance and existing literature. ${ }^{40-43}$

Finally, a subgroup analysis assessed the relationship between distance to cancer centers and CDT receipt among patients who received a medical oncology consultation. We thereby sought to determine whether distance influences access to therapy for patients who had a realized opportunity for therapy via medical oncology consultation.

All analyses were 2 sided, with statistical significance set at $P \leq .05$. Analyses were conducted using SAS Enterprise Guide 6.1 (SAS Institute Inc).

\section{Results}

A total of 15,970 patients were included (supplemental eFigure 2). Demographic and clinical characteristics of these patients are described in Table 1. In more recent years, patients were more likely to live closer to cancer centers.

\section{Outcomes}

A total of 10,473 patients $(65.6 \%)$ consulted a medical oncologist, and 6,142 (38.5\%) received CDT. Medical oncology consultation and CDT receipt were less likely with greater distance from cancer centers (Figure 1). Median survival was 3.30 months (interquartile range [IQR], 1.20-8.60 months) for the entire study cohort and was inferior for patients living farther from cancer centers, with median survival being 3.37 (IQR, 1.23-8.77), 3.33 (IQR, 1.20-8.53), 2.82 (IQR, 0.93-7.63), and 2.90 (IQR, $1.10-7.93)$ months for $\leq 10,11$ to 50,51 to 100 , and $\geq 101 \mathrm{~km}$, respectively $(P<.001)$.

\section{Geographic Mapping Analysis}

Univariate choropleth maps of each outcome variable exhibited regions of comparable survival and receipt of care (supplemental eFigures 3-5). Cancer centers were distributed unevenly, clustering heavily in the southern part of the province and particularly in the largest metropolitan area and nearby regions. Across geographic regions, median survival ranged from 1.9 to 5.2 months, medical oncology consultation from $32 \%$ to $80 \%$, and CDT receipt from $19 \%$ to $58 \%$.

Bivariate choropleth maps of overlapping outcomes across geographic regions showed concordantly high medical oncology consultation and high CDT use

\section{Table 1. Patient Characteristics}

\begin{tabular}{|c|c|c|c|c|c|c|}
\hline Characteristic & $\begin{array}{c}\leq 10 \mathrm{~km} \\
\mathrm{n}(\%)\end{array}$ & $\begin{array}{c}11-50 \mathrm{~km} \\
\mathrm{n}(\%)\end{array}$ & $\begin{array}{c}\text { 51-100 km } \\
\text { n (\%) }\end{array}$ & $\begin{array}{c}\geq 101 \mathrm{~km} \\
\mathrm{n}(\%)\end{array}$ & $\begin{array}{l}\text { All Patients } \\
\text { n (\%) }\end{array}$ & $P$ Value \\
\hline Patients, $\mathrm{n}$ & 9,656 & 4,473 & 1,072 & 769 & 15,970 & \\
\hline Age, y & & & & & & $<.001$ \\
\hline $18-60$ & $1,787(18.5)$ & $930(20.8)$ & $213(19.9)$ & $155(20.2)$ & $3,085(19.3)$ & \\
\hline $61-70$ & $2,307(23.9)$ & $1,258(28.1)$ & $265(24.7)$ & $193(25.1)$ & $4,023(25.2)$ & \\
\hline $71-80$ & $2,863(29.6)$ & $1,321(29.5)$ & $362(33.8)$ & $264(34.3)$ & $4,810(30.1)$ & \\
\hline $81-99$ & $2,699(28.0)$ & 964 (21.6) & $232(21.6)$ & $157(20.4)$ & $4,052(25.4)$ & \\
\hline Female sex & $4,904(50.8)$ & $2,114(47.3)$ & $525(49.0)$ & $342(44.5)$ & $7,885(49.4)$ & $<.001$ \\
\hline Year of diagnosis & & & & & & $<.001$ \\
\hline 2004-2010 & $4,506(46.7)$ & $2,027(45.3)$ & $546(50.9)$ & $395(51.4)$ & $7,474(46.8)$ & \\
\hline $2011-2017$ & $5,150(53.3)$ & $2,446(54.7)$ & $526(49.1)$ & $374(48.6)$ & $8,496(53.2)$ & \\
\hline High comorbidity burden (Elixhauser index $\geq 4$ ) & $1,468(15.2)$ & $693(15.5)$ & $191(17.8)$ & $126(16.4)$ & $2,478(15.5)$ & .139 \\
\hline Material deprivation quintile & & & & & & $<.001$ \\
\hline First (least deprived) & $1,589(16.5)$ & $1,098(24.6)$ & $142(13.2)$ & $98(12.7)$ & $2,927(18.3)$ & \\
\hline Second & $1,683(17.4)$ & $1,058(23.7)$ & $191(17.8)$ & $82(10.7)$ & $3,014(18.9)$ & \\
\hline Third & $1,709(17.7)$ & $968(21.6)$ & $247(23.0)$ & $156(20.3)$ & $3,080(19.3)$ & \\
\hline Fourth & $2,059(21.3)$ & $797(17.8)$ & $247(23.0)$ & $211(27.4)$ & $3,314(20.8)$ & \\
\hline Fifth (most deprived) & $2,616(27.1)$ & $552(12.3)$ & $245(22.9)$ & $222(28.9)$ & $3,635(22.8)$ & \\
\hline
\end{tabular}




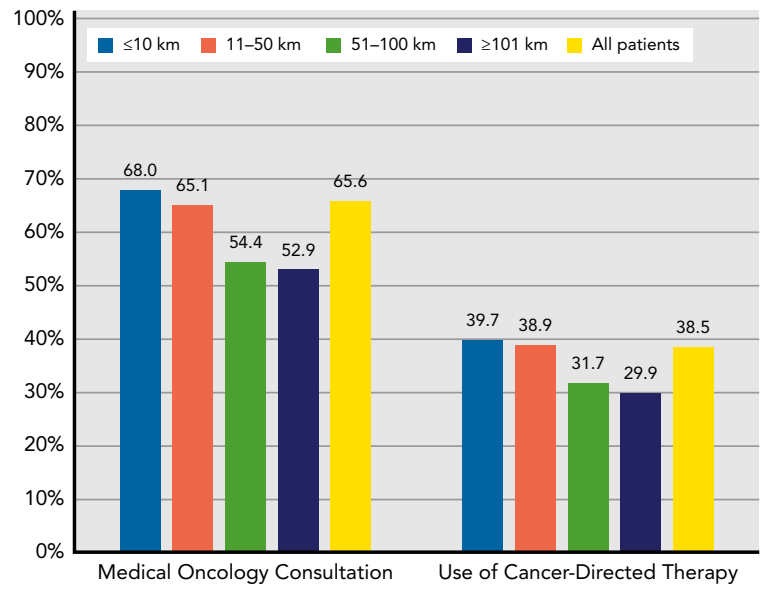

Figure 1. Medical oncology consultation and use of cancer-directed therapy, stratified by distance from residence to the nearest cancer care center.

concentrated in the largest metropolitan area and its adjacent regions, with concordantly low medical oncology consultation and low CDT use in the remote northern and less metropolitan southern regions of the province (Figure 2). Similar patterns were seen for medical oncology consultation and median survival (Figure 3) and for CDT receipt and median survival (Figure 4). A small number of nonadjacent geographic regions had discordant care-outcome patterns: low CDT receipt despite high oncology consultation (Figure 2), low survival despite high oncology consultation, high survival despite low oncology consultation (Figure 3), and high survival despite low CDT receipt (Figure 4).

\section{Association Between Distance to Cancer Centers and Outcomes}

Adjusted effect estimates of the association between distance to the nearest cancer center and outcomes are presented in Figure 5. Patients living 11 to $50 \mathrm{~km}$ and 51 to $100 \mathrm{~km}$ from the nearest center were significantly less likely to have medical oncology consultation than those living $\leq 10 \mathrm{~km}$ away. For patients living $\geq 101 \mathrm{~km}$ from care, the association did not reach significance, albeit with smaller numbers of patients $(n=769)$ and events $(n=362)$ in this group. No independent association between distance from the nearest center and CDT receipt was identified. Incremental distance from the nearest

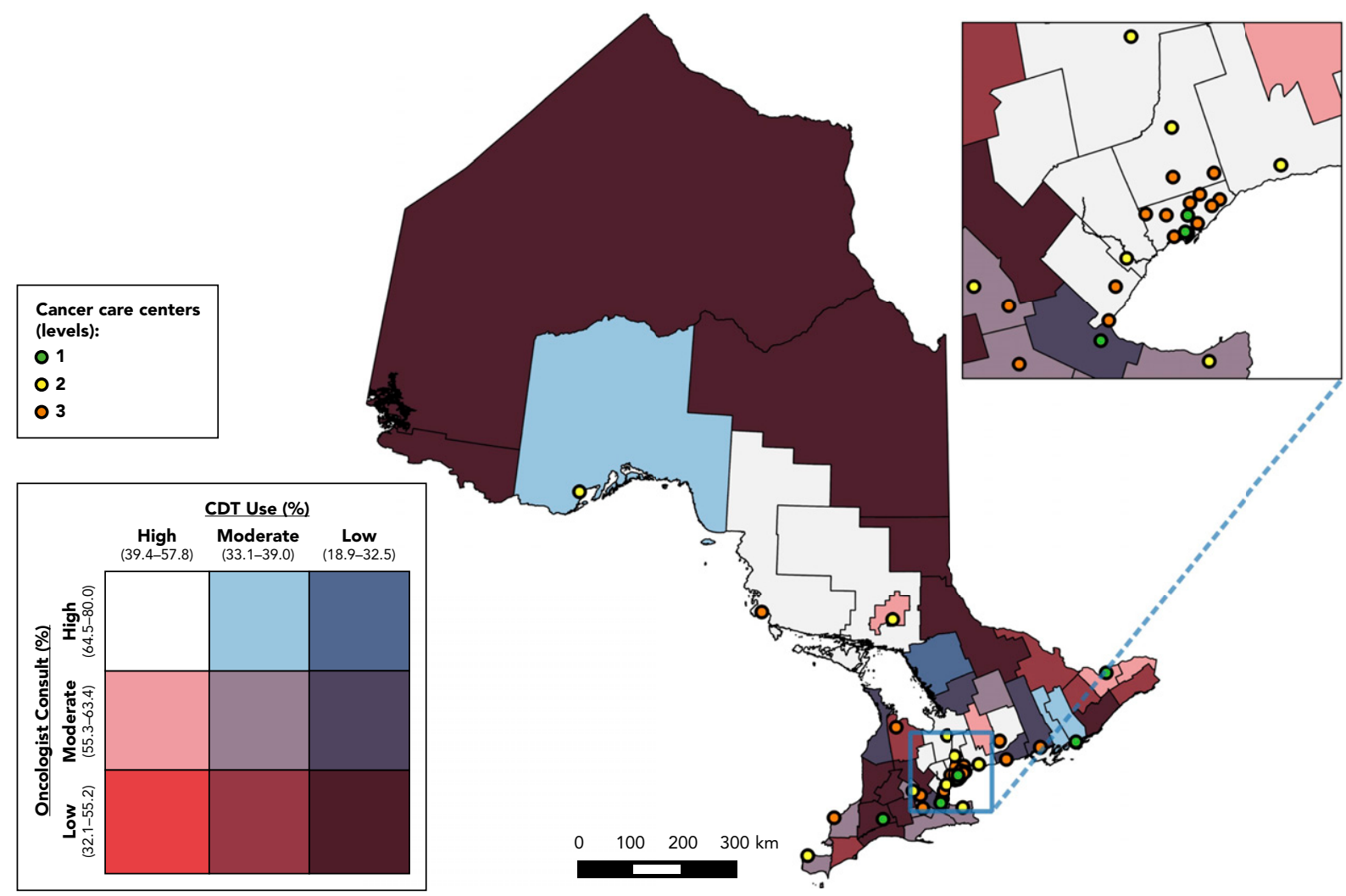

Figure 2. Bivariate choropleth map of the distribution of medical oncology consultation and CDT use by census division in Ontario, Canada. Low, moderate, and high values denote the first, second, and third tertiles, respectively, for each variable.

Abbreviation: CDT, cancer-directed therapy. 


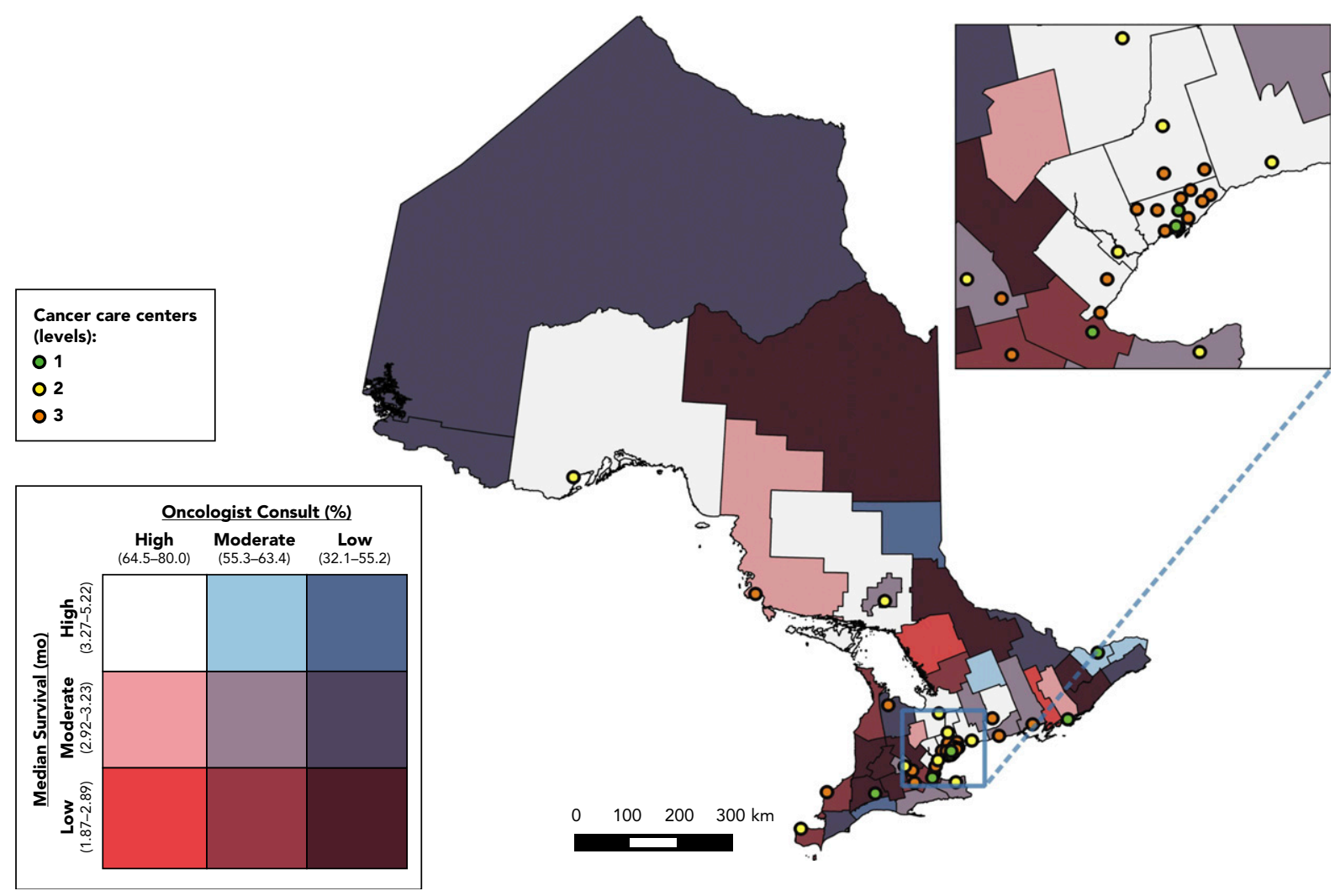

Figure 3. Bivariate choropleth map of the distribution of medical oncology consultation and median survival by census division in Ontario, Canada. Low, moderate, and high values denote the first, second, and third tertiles, respectively, for each variable.

center was independently associated with a reduction in survival, with hazard ratios (HRs) of 1.08 (95\% CI, $1.04-1.12$ ) for 11 to $50 \mathrm{~km}, 1.17$ (95\% CI, 1.10-1.25) for 51 to $100 \mathrm{~km}$, and 1.10 (95\% CI, $1.02-1.18)$ for $\geq 101 \mathrm{~km}$. When we restricted the cohort to the 10,473 patients who had a medical oncology consultation, the lack of association between distance and CDT receipt persisted.

\section{Discussion}

WHO defines 3 dimensions of access to care: physical accessibility, financial affordability, and acceptability. ${ }^{44}$ Because the Canadian public healthcare system provides access that is not confounded by insurance status, our study was ideally situated to examine the impact of physical accessibility. We identified that residing a greater distance from the nearest cancer center was associated with lower likelihood of medical oncology consultation and inferior survival. The association between distance to the nearest cancer center and CDT receipt did not reach statistical significance. We outlined regional disparities in medical oncology consultation, CDT receipt, and survival. We also observed specific regions with unique interactions between medical oncology consultation and CDT receipt and between survival and each of medical oncology consultation and CDT receipt.
Much of the existing literature concerning distanceoutcome relationships in cancer has focused on surgically treatable cancers. ${ }^{12,14,28,45-47}$ Previous work has indicated that farther distance to care centers is associated with higher stage at diagnosis and lower rates of consultation, treatment, palliative care engagement, and survival. ${ }^{12,14,29,45,48-52}$ Few studies have examined this relationship in the context of systemic therapy for noncurable pancreatic adenocarcinoma. A geographic analysis of advanced pancreatic cancer found no difference in survival between rural and urban residence, albeit within a sample of patients who had already received chemotherapy, with some having undergone curative-intent resection. ${ }^{53} \mathrm{~A}$ different study of unresected pancreatic cancer indicated that rural living negatively impacted oncology consultation but not receipt of chemotherapy. ${ }^{54}$ A similar pattern was also observed for radiation therapy delivery, whereby greater distance was inversely associated with radiation oncology consultation but not with receipt of therapy. ${ }^{29}$

Our analysis is unique because it reports on $>15,000$ patients, combines data on both access to care and receipt of therapy, and assesses both patient-level and region-level trajectories in accessing specialized cancer care. The large sample size facilitated a detailed 


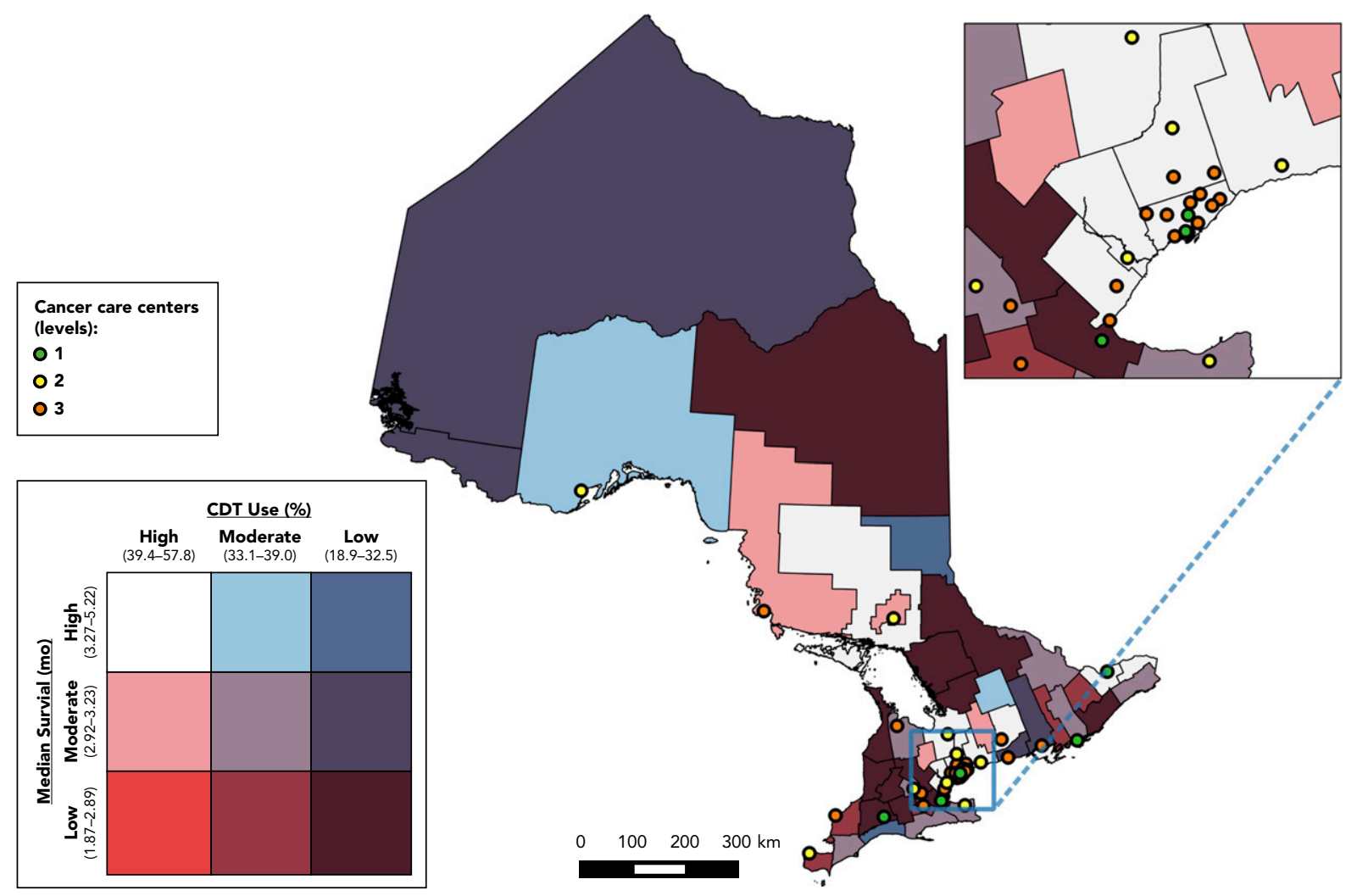

Figure 4. Bivariate choropleth map of the distribution of CDT use and median survival by census division in Ontario, Canada. Low, moderate, and high values denote the first, second, and third tertiles, respectively, for each variable.

Abbreviation: CDT, cancer-directed therapy.

assessment of distance and geography, adjusting for potential confounders. Unlike prior studies relying on distance as a sole measure of geographic access, we also obtained a regional perspective by visually examining outcome disparities in relation to locations of cancer centers. This approach provided information to assess healthcare disparities at the patient and system levels. Although the former is important for individualized care, the latter is crucial for establishing care pathways and strategies to address disparities. Moreover, we considered multiple outcomes across the care continuum, capturing the interplay between different care steps and survival.

We identified specific trends within the distanceoutcome relationship. An inverse association was observed between distance to cancer centers and receipt of medical oncology consultation. Distance was not statistically associated with CDT receipt. With the low proportion of patients with noncurable pancreatic adenocarcinoma receiving CDT, this may have been due to lack of power. However, it may also suggest that access to a medical oncologist is the primary barrier for those living far from cancer centers. This could be due to the delivery of systemic therapy in satellite centers without onsite medical oncologists, thereby mitigating the impact of distance on therapy receipt. For CDT to be received, medical oncology consultation is required, which seemed to be limited by availability and distance. The low rate of CDT receipt in the cohort is consistent with prior reports. ${ }^{3-7}$ Nevertheless, low CDT receipt out of proportion with medical oncology consultation in the cohort at large suggests possible undertreatment at the provider level, emphasizing a previously identified need for informed discussion about CDT between patients and clinicians. $^{3}$

Although survival was inferior at all distances compared with the closest distance category, the hazard of death was greatest for patients living 51 to $100 \mathrm{~km}$ from the nearest cancer center. This is consistent with previous work showing that the distance-survival relationship may be nonlinear in cancer care,$^{28}$ and suggests that protective factors may mitigate the impact of distance on survival at extreme distances. Prior work has revealed that patients traveling longer distances for cancer care often have better outcomes, possibly due to unmeasured characteristics, such as overall health allowing them to travel farther. ${ }^{55}$ Because we looked at potential travel distances rather than realized travel distances, this would not have impacted our results. Although elucidation of 


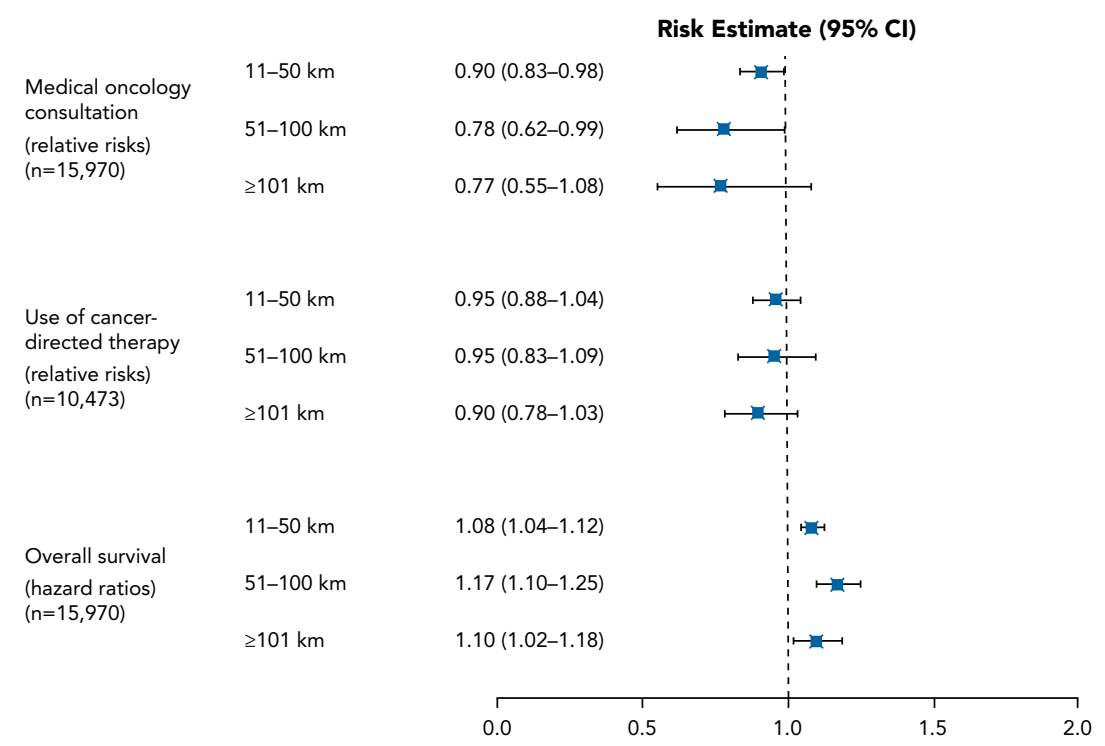

Figure 5. Adjusted risk estimates for the association between distance from residence to the nearest cancer center and medical oncology consultation, use of cancer-directed therapy, and overall survival (reference category, $\leq 10 \mathrm{~km}$ ). Models were adjusted for age at diagnosis, sex, year of diagnosis, comorbidity burden, and material deprivation quintile. Blue squares denote risk estimate, bars denote $95 \%$ confidence intervals, and dotted line denotes risk estimate of 1.

the exact mechanisms underlying this finding was beyond the scope of this study, there are several possibilities. Patients living remotely may benefit from more cohesive social supports within smaller and more rural communities. ${ }^{56}$ Unique health services, such as telemedicine, may facilitate oncologist consultation, with subsequent receipt of therapy at satellite centers. ${ }^{57}$ In addition, given that they must travel far distances to reach even their closest centers, remote patients may more frequently bypass these centers to access cancer services in larger communities and thus receive care from highervolume providers with superior outcomes. ${ }^{58,59}$ Planning of cancer care should pay particular attention to patients living at moderate distances from cancer centers and potentially learn from measures in place for those living at extreme distances.

It is important to appreciate spatial relationships and interplay between care delivery and outcomes in order to implement targeted interventions. The maps in this analysis visualize these relationships. Bivariate choropleth maps also provide a qualitative means of identifying areas of unwarranted variation between outcomes that would suggest opportunities for interventions. Low survival despite high oncology consultation could represent unmeasured inefficiencies after entering the cancer care system, such as delays between consultation and treatment. Patient preferences or provider practice patterns, including provider clinical volume, favoring less-aggressive treatment approaches may also play a role. ${ }^{59}$ High survival despite low medical oncology consultation occurred in regions that also had lower rates of CDT. This trend could therefore be due to regional biases toward more aggressive treatment among those who do receive CDT, offsetting low survival among those who do not. It may also represent protective factors outside of the formal cancer care system, such as support programs within the community, that could be leveraged in other jurisdictions. This work thereby provides a framework that can be used by health systems to develop interventions aimed at minimizing geographic disparities.

Our study had limitations. We used healthcare administrative datasets that were not collected specifically to address the research question, such that some confounders could not be adjusted for, such as tumor burden. The observation that distance to care has decreased over time with the opening of new cancer centers raises the possibility of confounding of shorter distances with secular trends of improving outcomes in care, despite adjustment for year of diagnosis. It is also possible that patients living at the greatest distance received care in another province that was at a shorter travel distance. However, such movement is rare because the Canadian public healthcare system is managed at the provincial level. Because the maps presented in this study use data aggregated to CDs, apparent geospatial trends are potentially biased by the modifiable areal unit problem, whereby the values ascribed to the aggregating units are sensitive to the geographically arbitrary boundaries of those same units. ${ }^{60}$ Any conclusions drawn from these maps are 
ecologic and do not account for sub-CD level variations in care use and survival. Rather, this qualitative methodology can guide quantitative analyses and facilitate future studies of regional mechanisms underlying disparate care and outcomes. Finally, the true population-based design of this work is a strength, with continuous data collection and data encompassing all patients in a jurisdiction within a universal healthcare system in which insurance status does not interfere with receipt of care.

\section{Conclusions}

For patients diagnosed with noncurable pancreatic adenocarcinoma, residing a greater distance from the nearest cancer center was associated with lower likelihood of medical oncology consultation and inferior survival, but it did not influence CDT receipt. This suggests that remote residence and distribution of centers pose a barrier to accessing the cancer care system and obtaining assessment via medical oncology consultation. Patients living at moderate distances from centers may be most vulnerable to disparities in survival and access to systemic therapies. Better geographic and clinical access to medical oncology is critical in improving outcomes and lessening disparities for noncurable pancreatic adenocarcinoma, which will require interventions tailored at the regional level.
Submitted March 5, 2020; accepted for publication June 18, 2020.

Previous presentation: Part of this work was presented at the GeoHealth Conference, April 30, 2019, Toronto, Ontario; the University of Toronto Department of Surgery Gallie Day, May 3, 2019, Toronto; the University of Toronto Department of Surgery Annual Assembly, May 16, 2019, Toronto; the annual meeting of the Canadian Society of Surgical Oncology, May 3, 2019 Toronto; and the Canadian Surgery Forum, September 5-7, 2019, Montreal, Quebec, Canada.

Author contributions: Statistical analysis: Liu. Study design and analysis: Coburn, Davis, Mahar, Zuk, Gupta, Earle. Manuscript preparation: Yee, Hallet. Suggestions for final manuscript: Coburn, Davis, Mahar, Zuk, Gupta, Earle.

Disclosures: Dr. Coburn has disclosed that she receives salary support from Cancer Care Ontario. Dr. Hallet has disclosed that she has received honoraria from Ipsen Biopharmaceuticals Canada and Novartis Oncology. The remaining authors have disclosed that they have not received any financial consideration from any person or organization to support the preparation, analysis, results, or discussion of this article.

Funding: This study was supported by the Institute of Clinical Evaluative Sciences (ICES), which is funded by an annual grant from the Ontario Ministry of Health and Long-Term Care (MOHLTC). This study was supported by an operating grant from the Canadian Institutes of Health Research (FRN \#154131).

Disclaimer: The opinions, results, and conclusions reported in this paper are those of the authors and are independent from the funding sources. No endorsement by ICES or the Ontario MOHLTC is intended or should be inferred. Parts of this material are based on data and information compiled and provided by the Canadian Institute for Health Information (CIHI). However, the analyses, conclusions, opinions, and statements expressed herein are those of the authors and not necessarily those of $\mathrm{ClHI}$. Parts of this material are based on data and information provided by Cancer Care Ontario (CCO). The opinions, results, views, and conclusions reported in this paper are those of the authors and do not necessarily reflect those of CCO. No endorsement by CCO is intended or should be inferred.

Correspondence: Julie Hallet, MD, MSc, Department of Surgery, Odette Cancer Centre - Sunnybrook Health Sciences Centre, 2075 Bayview Avenue, Toronto, ON, M4N 3M5, Canada. Email: julie.hallet@sunnybrook.ca

\section{References}

1. Huang $L$, Jansen $L$, Balavarca $Y$, et al. Resection of pancreatic cancer in Europe and USA: an international large-scale study highlighting large variations. Gut 2019;68:130-139.

2. Canadian Cancer Statistics Advisory Committee. Canadian Cancer Statistics 2018. Toronto, Ontario, Canada: Canadian Cancer Society; 2018.

3. Mavros MN, Coburn NG, Davis LE, et al. Low rates of specialized cancer consultation and cancer-directed therapy for noncurable pancreatic adenocarcinoma: a population-based analysis. CMAJ 2019;191:E574-580.

4. Abdel-Rahman O, Xu Y, Tang PA, et al. A real-world, population-based study of patterns of referral, treatment, and outcomes for advanced pancreatic cancer. Cancer Med 2018;7:6385-6392.

5. Khanal N, Upadhyay S, Dahal S, et al. Systemic therapy in stage IV pancreatic cancer: a population-based analysis using the National Cancer Data Base. Ther Adv Med Oncol 2015;7:198-205.

6. Sharp $L$, Carsin AE, Cronin-Fenton DP, et al. Is there under-treatment of pancreatic cancer? Evidence from a population-based study in Ireland. Eur J Cancer 2009;45:1450-1459.

7. Krzyzanowska MK, Weeks JC, Earle CC. Treatment of locally advanced pancreatic cancer in the real world: population-based practices and effectiveness. J Clin Oncol 2003;21:3409-3414.

8. Von Hoff DD, Ervin T, Arena FP, et al. Increased survival in pancreatic cancer with nab-paclitaxel plus gemcitabine. N Engl J Med 2013;369: 1691-1703.

9. Sohal DPS, Kennedy EB, Khorana A, et al. Metastatic pancreatic cancer: ASCO clinical practice guideline update. J Clin Oncol 2018;36: 2545-2556.

10. Conroy $T$, Desseigne $F$, Ychou M, et al. FOLFIRINOX versus gemcitabine for metastatic pancreatic cancer. N Engl J Med 2011;364:1817-1825.

11. Sinding C, Warren R, Fitzpatrick-Lewis $D$, et al. Research in cancer care disparities in countries with universal healthcare: mapping the field and its conceptual contours. Support Care Cancer 2014;22:3101-3120.

12. O'Connor SC, Mogal H, Russell G, et al. The effects of travel burden on outcomes after resection of extrahepatic biliary malignancies: results from the US Extrahepatic Biliary Consortium. J Gastrointest Surg 2017;21: 2016-2024.

13. Raphael MJ, Siemens DR, Booth CM. Would regionalization of systemic cancer therapy improve the quality of cancer care? J Oncol Pract 2019;15: 349-356.

14. Lin CC, Bruinooge SS, Kirkwood MK, et al. Association between geographic access to cancer care, insurance, and receipt of chemotherapy: geographic distribution of oncologists and travel distance. J Clin Oncol 2015;33:3177-3185

15. Latchana N, Davis L, Coburn NG, et al. Population-based study of the impact of surgical and adjuvant therapy at the same or a different institution on survival of patients with pancreatic adenocarcinoma. BJS Open 2018;3:85-94.

16. Government of Canada: Focus on geography series, 2016 census. Province of Ontario. Accessed November 6, 2020. Available at: https:// www12.statcan.gc.ca/census-recensement/2016/as-sa/fogs-spg/ Facts-pr-eng. $\mathrm{cfm}$ ? Lang $=$ Eng \&GK $=$ PR\&GC $=35 \&$ TOPIC $=1$

17. Government of Canada. Canada Health Act. Accessed August 21, 2019 Available at: https://www.canada.ca/en/health-canada/services/healthcare-system/canada-health-care-system-medicare/canada-health-act. html

18. Benchimol El, Smeeth L, Guttmann A, et al. The REporting of studies Conducted using Observational Routinely-collected health Data (RECORD) statement. PLoS Med 2015;12:e1001885.

19. Hammad A, Davis LE, Mahar AL, et al. Symptom trajectories and predictors of severe symptoms in pancreatic adenocarcinoma at the end-oflife: a population based analysis of 2,538 patients. HPB (Oxford) 2019;21: 1744-1752.

20. Iron K, Zagorski BM, Sykora K, et al. Living and Dying in Ontario: An Opportunity for Improved Health Information. ICES Investigative Report. Toronto, Ontario, Canada: Institute for Clinical Evaluative Sciences (ICES); 2008. 
21. Robles SC, Marrett LD, Clarke EA, et al. An application of capturerecapture methods to the estimation of completeness of cancer registration. J Clin Epidemiol 1988;41:495-501.

22. Juurlink D, Preyra C, Croxford R, et al. Canadian Institute for Health Information Discharge Abstract Database: A Validation Study. ICES Investigative Report. Toronto, Ontario, Canada: Institute for Clinical Evaluative Sciences (ICES); 2006.

23. Government of Canada, Statistics Canada. Postal CodeOM Conversion File. Accessed August 21, 2019. Available at: https://www150.statcan.gc. $\mathrm{ca} / \mathrm{n} 1 / \mathrm{en} /$ catalogue/92-154-X

24. Government of Canada, Statistics Canada. Census divisions. Accessed August 21, 2019. Available at: https://www12.statcan.gc.ca/censusrecensement/2016/dp-pd/hlt-fst/imm/GeoSelect-eng.cfm? Lang $=\mathrm{E} \& \mathrm{~T}=23$

25. Government of Canada, Statistics Canada. 2016 Census - Boundary files Accessed August 21, 2019. Available at: https://www12.statcan.gc.ca/ census-recensement/2011/geo/bound-limit/bound-limit-2016-eng.cfm

26. Cancer Care Ontario; Action Cancer Ontario. Quality Person-Centred Systemic Treatment in Ontario: 2014-2019 Systemic Treatment Provincial Plan. Cancer Care Ontario. Accessed November 6, 2020. Available at: https://www.cancercareontario.ca/en/cancer-care-ontario/programs/clinical-services/systemic-treatment/provincial-plan

27. Paszat LF, Mackillop WJ, Groome PA, et al. Radiotherapy for breast cancer in Ontario: rate variation associated with region, age and income. Clin Invest Med 1998;21:125-134.

28. Kim YE, Gatrell AC, Francis BJ. The geography of survival after surgery for colo-rectal cancer in southern England. Soc Sci Med 2000;50:1099-1107.

29. Johnston GM, Boyd CJ, Joseph $P$, et al. Variation in delivery of palliative radiotherapy to persons dying of cancer in Nova Scotia, 1994 to 1998. $\mathrm{J}$ Clin Oncol 2001;19:3323-3332.

30. Townsley C, Pond GR, Peloza B, et al. Analysis of treatment practices for elderly cancer patients in Ontario, Canada. J Clin Oncol 2005;23: 3802-3810.

31. Groome PA, Schulze KM, Keller S, et al. Demographic differences between cancer survivors and those who die quickly of their disease. Clin Oncol (R Coll Radiol) 2008;20:647-656.

32. Alvino DML, Chang DC, Adler JT, et al. How far are patients willing to travel for gastrectomy? Ann Surg 2017;265:1172-1177.

33. Fong ZV, Loehrer AP, Fernández-Del Castillo $C$, et al. Potential impact of a volume pledge on spatial access: a population-level analysis of patients undergoing pancreatectomy. Surgery 2017;162:203-210.

34. Meilleur A, Subramanian SV, Plascak JJ, et al. Rural residence and cancer outcomes in the United States: issues and challenges. Cancer Epidemiol Biomarkers Prev 2013;22:1657-1667

35. Matheson FI, Moloney G, van Ingen T. 2016 Ontario Marginalization Index: User Guide. Toronto, Ontario, Canada: St. Michael's Hospital/ Public Health Ontario; 2018.

36. Elixhauser A, Steiner C, Harris DR, et al. Comorbidity measures for use with administrative data. Med Care 1998;36:8-27.

37. Gutacker N, Bloor K, Cookson R. Comparing the performance of the Charlson/Deyo and Elixhauser comorbidity measures across five European countries and three conditions. Eur J Public Health 2015;25(Suppl 1):15-20.

38. Brewer CA. Basic mapping principles for visualizing cancer data using Geographic Information Systems (GIS). Am J Prev Med 2006;30(2, Suppl): S25-36.

39. Sears J, Khan $\mathrm{K}$, Ardern $\mathrm{Cl}$, et al. Potential for patient-physician language discordance in Ontario. BMC Health Serv Res 2013;13:535.

40. Maddison AR, Asada $Y$, Urquhart R. Inequity in access to cancer care: a review of the Canadian literature. Cancer Causes Control 2011;22: 359-366.
41. Groux P, Anchisi S, Szucs T. Are cancer patients willing to travel more or further away for a slightly more efficient therapy? Cancer Clin Oncol 2014; 3:36-42.

42. Resio BJ, Chiu AS, Hoag JR, et al. Motivators, barriers, and facilitators to traveling to the safest hospitals in the United States for complex cancer surgery. JAMA Netw Open 2018;1:e184595.

43. Symer MM, Abelson JS, Yeo HL. Barriers to regionalized surgical care: public perspective survey and geospatial analysis. Ann Surg 2019;269: 73-78.

44. Evans DB, Hsu J, Boerma T. Universal health coverage and universal access. Bull World Health Organ 2013;91:546-546A.

45. Dejardin O, Bouvier AM, Faivre J, et al. Access to care, socioeconomic deprivation and colon cancer survival. Aliment Pharmacol Ther 2008;27: 940-949.

46. Stitzenberg KB, Sigurdson ER, Egleston BL, et al. Centralization of cancer surgery: implications for patient access to optimal care. J Clin Oncol 2009. 27:4671-4678.

47. Lidsky ME, Sun Z, Nussbaum DP, et al. Going the extra mile: improved survival for pancreatic cancer patients traveling to high-volume centers. Ann Surg 2017;266:333-338.

48. Tracey E, McCaughan B, Badgery-Parker T, et al. Patients with localized non-small cell lung cancer miss out on curative surgery with distance from specialist care. ANZ J Surg 2015;85:658-663.

49. Burge FI, Lawson BJ, Johnston GM, et al. A population-based study of age inequalities in access to palliative care among cancer patients. Med Care 2008;46:1203-1211.

50. Turner M, Fielding S, Ong $Y$, et al. A cancer geography paradox? Poorer cancer outcomes with longer travelling times to healthcare facilities despite prompter diagnosis and treatment: a data-linkage study. $\mathrm{Br} \mathrm{J}$ Cancer 2017;117:439-449.

51. Massarweh NN, Chiang YJ, Xing Y, et al. Association between travel distance and metastatic disease at diagnosis among patients with colon cancer. J Clin Oncol 2014;32:942-948.

52. Duff JM, Thomas RM. Impact of palliative chemotherapy and travel distance on hospice referral in patients with stage IV pancreatic cancer: a retrospective analysis within a Veterans Administration medical center. Am J Hosp Palliat Care 2018;35:875-881.

53. Canale TD, Cho H, Cheung WY. A population-based analysis of urbanrural disparities in advanced pancreatic cancer management and outcomes. Med Oncol 2018;35:116.

54. Dumbrava MI, Burmeister EA, Wyld D, et al. Chemotherapy in patients with unresected pancreatic cancer in Australia: a population-based study of uptake and survival. Asia Pac J Clin Oncol 2018;14:326-336.

55. Lamont EB, Hayreh D, Pickett KE, et al. Is patient travel distance associated with survival on phase II clinical trials in oncology? J Natl Cancer Inst 2003;95:1370-1375.

56. Ahmed S, Shahid RK. Disparity in cancer care: a Canadian perspective.Curr Oncol 2012;19:e376-382.

57. O'Gorman LD, Hogenbirk JC, Warry W. Clinical telemedicine utilization in Ontario over the Ontario Telemedicine Network. Telemed J E Health 2016;22:473-479

58. Baldwin LM, Cai Y, Larson EH, et al. Access to cancer services for rural colorectal cancer patients. J Rural Health 2008;24:390-399.

59. Hallet J, Davis L, Mahar A, et al. Benefits of high-volume medical oncology care for noncurable pancreatic adenocarcinoma: a population-based analysis. J Natl Compr Canc Netw 2020;18:297-303.

60. Openshaw S. The modifiable areal unit problem. Concepts and Techniques in Modern Geography No. 38. Norwich, UK: Geo Books; 1983.

See JNCCN.org for supplemental online content. 
Supplemental online content for:

\section{Impact of Geography on Care Delivery and Survival for Noncurable Pancreatic Adenocarcinoma: A Population-Based Analysis}

Elliott K. Yee, B.Arts Sc.; Natalie G. Coburn, MD, MPH; Laura E. Davis, MSc; Alyson L. Mahar, PhD; Victoria Zuk, MSc; Vaibhav Gupta, MD, PhD; Ying Liu, MSc; Craig C. Earle, MD, MSc; and Julie Hallet, MD, MSc

J Natl Compr Canc Netw 2020;18(12):1642-1650

eFigure 1: Reference Map of Census Divisions in Ontario eFigure 2: Flow Diagram of Cohort Creation eFigure 3: Univariate Choropleth Map of Medical Oncology Consultation eFigure 4: Univariate Choropleth Map of Use of Cancer-Directed Therapy eFigure 5: Univariate Choropleth Map of Median Survival eTable 1: Main Variable Definitions eTable 2: Data Sources eAppendix 1: Details of Statistical Analyses 


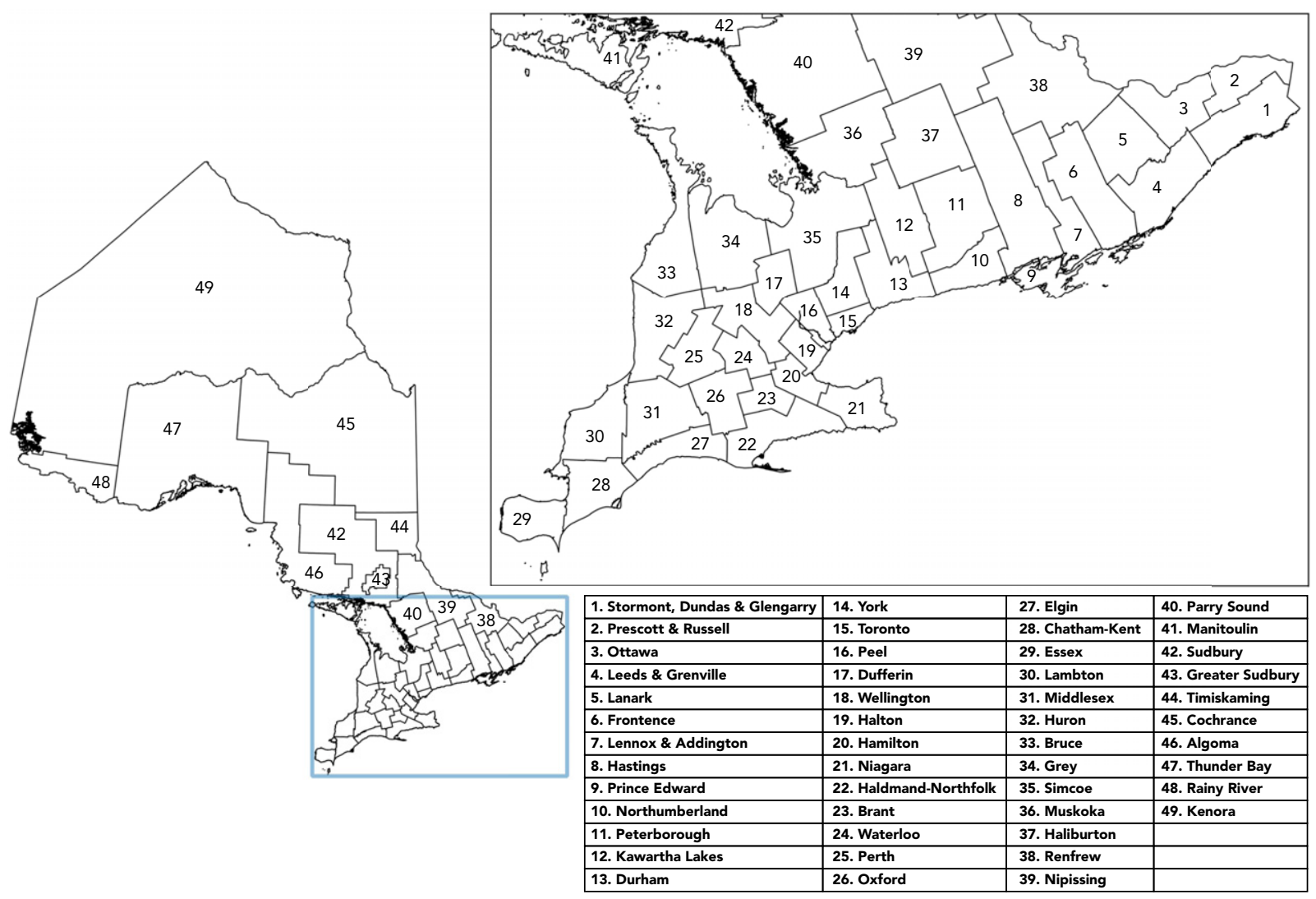

eFigure 1. Reference map of census divisions in Ontario.

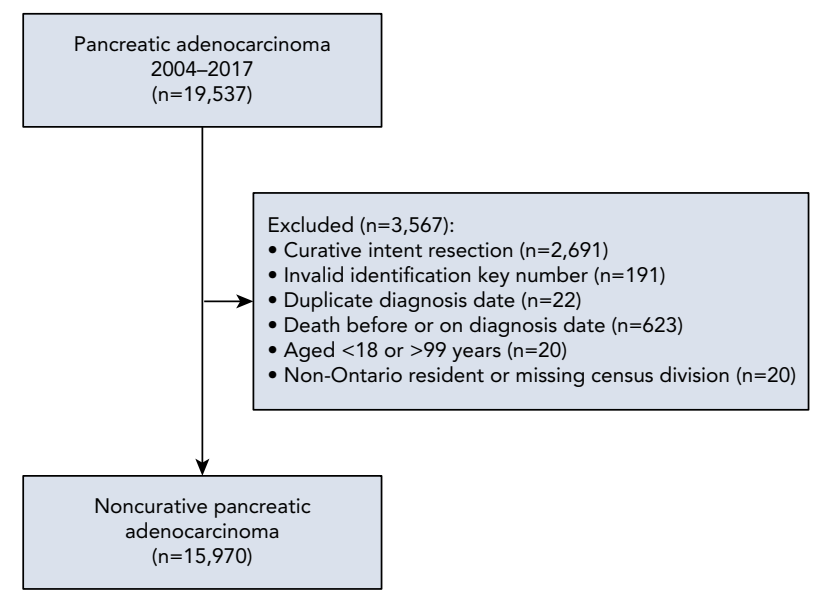

eFigure 2. Flow diagram of cohort creation. 


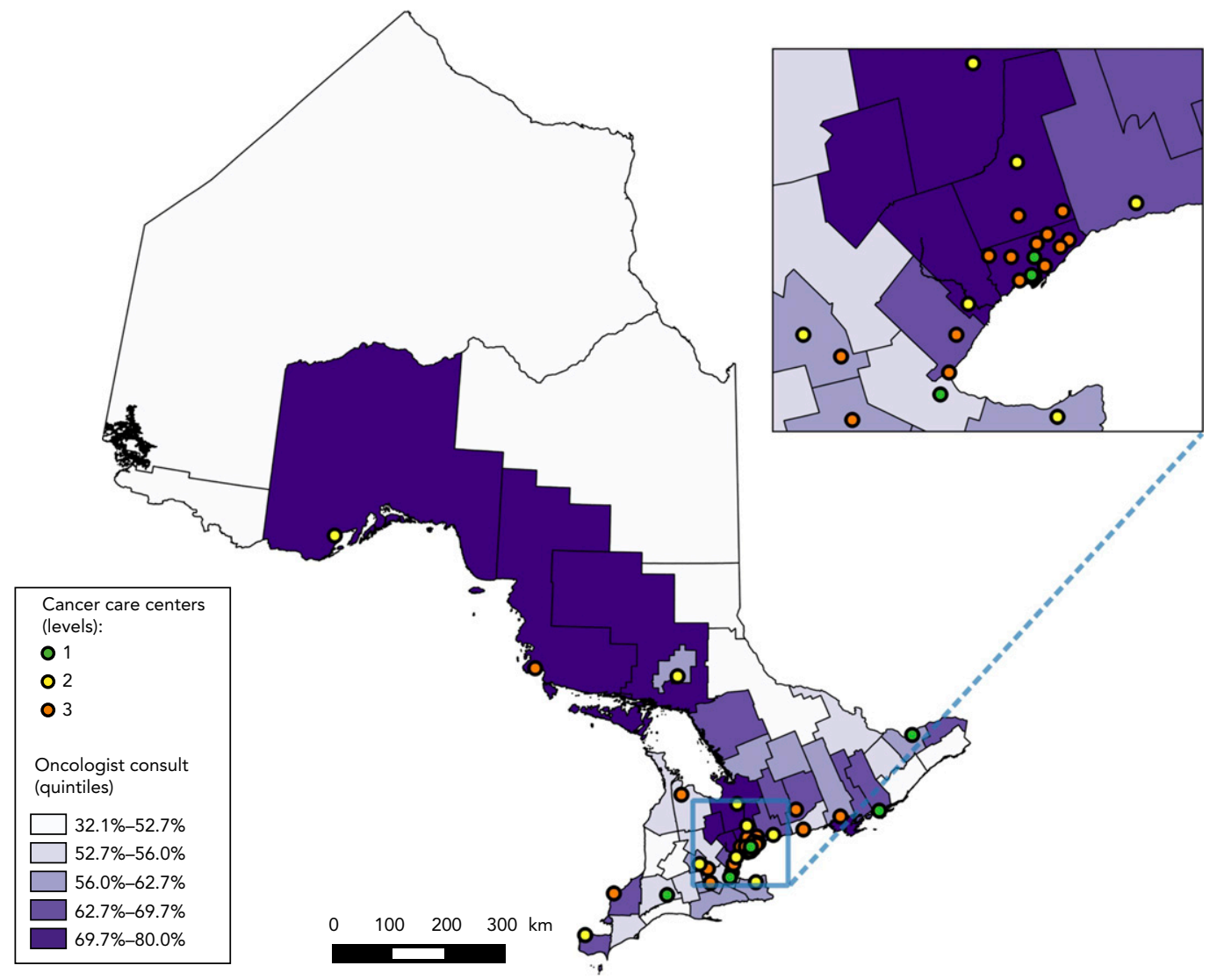

eFigure 3. Univariate choropleth map of medical oncology consultation by census division in Ontario, Canada. 


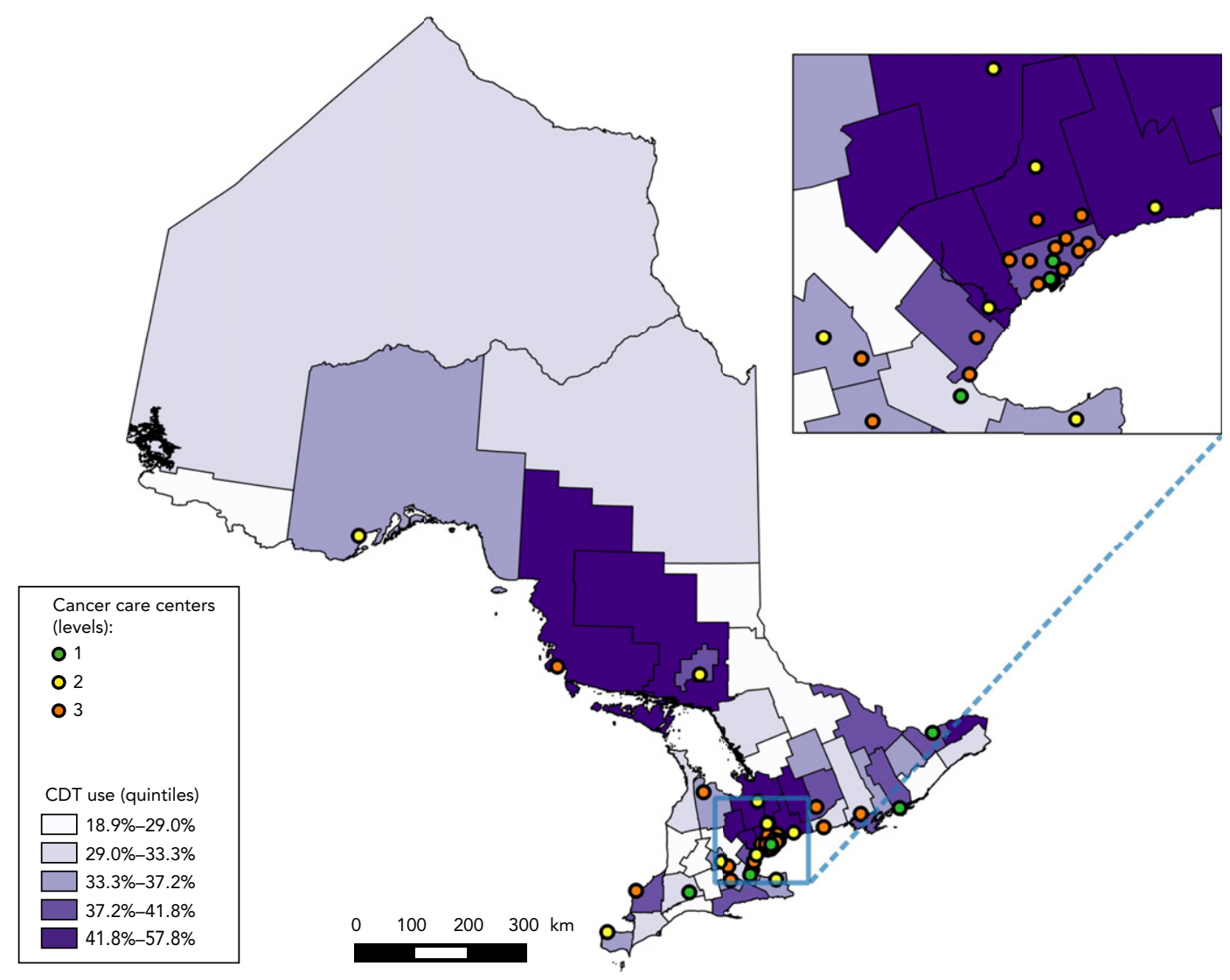

eFigure 4. Univariate choropleth map of use of CDT by census division in Ontario, Canada. Abbreviation: CDT, cancer-directed therapy. 


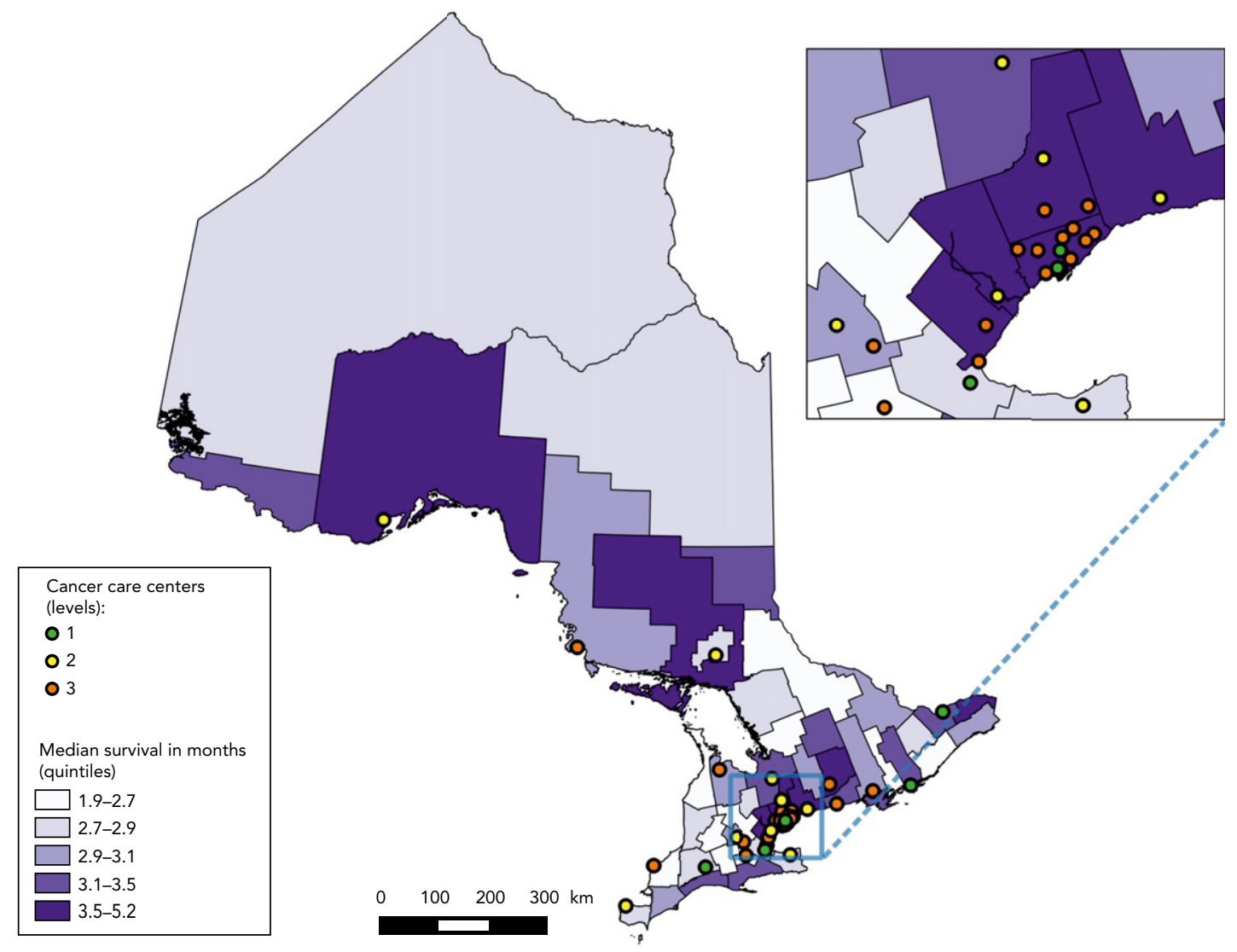

eFigure 5. Univariate choropleth map of median survival by census division in Ontario, Canada. 


\section{eTable 1. Main Variable Definitions}

\begin{tabular}{|c|c|c|}
\hline Variable & Data Source & Code Strategy \\
\hline Pancreatectomy (exclusion) & $\begin{array}{l}\mathrm{ClHI} \\
\mathrm{OHIP}\end{array}$ & $\begin{array}{l}\text { Pancreaticoduodenectomy: } 10 \mathrm{~K} 87 \\
\text { Total pancreatectomy: } 1 \text { OK } 91,10 \mathrm{O} 89,10 \mathrm{~K} 89 \\
\text { Distal pancreatectomy: } 1 \text { OJ87 (except for } 1 \text { OJ87VC) or OHIP codes S300, } \\
\text { S299, S309, S301 }\end{array}$ \\
\hline Sex & RPDB & - \\
\hline Income quintile & $\begin{array}{l}\text { Canadian Census } \\
\text { RPDB }\end{array}$ & Ecologic measure of income ${ }^{1}$ \\
\hline Year of diagnosis & OCR & - \\
\hline Comorbidity burden & $\begin{array}{l}\text { CIHI Discharge Abstract Database } \\
\text { CIHI Same Day Surgery } \\
\text { National Ambulatory Care Reporting } \\
\text { System } \\
\text { OHIP }\end{array}$ & ICD codes for Elixhauser index ${ }^{2,3}$ \\
\hline Medical oncology consultation & OHIP & $\begin{array}{l}\text { Medical oncology physician: physician billing G381, G281, G339, G345, G359 } \\
\text { Consultation codes: A130, A131, A133, A134, A135, A136, A138, A441, A435, } \\
\text { A443, A444, A445, A446, A448, A611, A613, A614, A615, A616, A618, A655, } \\
\text { A845, C443, C444, C445, C446, C845 }\end{array}$ \\
\hline Receipt of chemotherapy & $\begin{array}{l}\text { OHIP } \\
\text { ALR }\end{array}$ & $\begin{array}{l}\geq 1 \text { cycle of chemotherapy defined as OHIP codes G281, G339, G345, G359, } \\
\text { G381 or ALR drug codes S1, S17, S24 (counted only once if both ALR and } \\
\text { OHIP codes are present) }\end{array}$ \\
\hline Receipt of chemoradiation & $\begin{array}{l}\text { OHIP } \\
\text { ALR }\end{array}$ & $\begin{array}{l}\geq 1 \text { chemotherapy billing code with a radiation therapy billing code } \\
\text { Chemotherapy: OHIP codes G381, G281, G339, G345, G359 } \\
\text { Radiation therapy: ALR codes } 120,130,503,510,511,512,519,520,521,522, \\
523,524,525,526,527,528,529,530,531,532,533,534,535,536,537,538, \\
539,540,541,542,548,549,561,563,565,566,568,570,571,572,573,574, \\
575,581,582,590,591,592,594,596,597\end{array}$ \\
\hline
\end{tabular}

Abbreviations: ALR, Activity Level Reporting; CIHI, Canadian Institute for Health Information; OCR, Ontario Cancer Registry; OHIP, Ontario Health Insurance Plan; RPDB, Registered Persons Database.

\section{References}

1. Alter DA, Naylor CD, Austin P, et al. Effects of socioeconomic status on access to invasive cardiac procedures and on mortality after acute myocardial infarction. N Engl J Med 1999;341:1359-1367.

2. Elixhauser A, Steiner C, Harris DR, et al. Comorbidity measures for use with administrative data. Med Care 1998;36:8-27.

3. Gutacker N, Bloor K, Cookson R. Comparing the performance of the Charlson/Deyo and Elixhauser comorbidity measures across five European countries and three conditions. Eur J Public Health 2015;25(Suppl 1):15-20.

4. Matheson FI, Dunn JR, Smith KL, et al. Development of the Canadian Marginalization Index: a new tool for the study of inequality. Canadian J Public Health 2012 103(Suppl 2):S12-16.

5. Krieger N. Overcoming the absence of socioeconomic data in medical records: validation and application of a census-based methodology. Am J Public Health 1992;82:703-710. 
eTable 2. Data Sources

Database

\section{Description}

OCR

The OCR is a passive provincial registry of all incident cancer diagnoses in Ontario. It includes $96 \%$ of cancer diagnoses in the province. Information included in the registry: cancer topography and morphology/histology and details of diagnosis (eg, types of information contributing to the diagnosis, dates).

ALR of Cancer Care Ontario Cancer Care Ontario maintains a database of cancer-specific services, including consultations, chemotherapy, and radiotherapy provided by RCCs in the province. Because all radiotherapy is delivered at RCCs, it is a complete source of information. However, because not all patients with cancer who receive surgery or chemotherapy visit an RCC, it cannot be used as a population data source for those treatments.

RPDB The RPDB is an ICES database derived from all administrative data sources and provides demographic data, including age, patient residence, vital status, date of last contact with the healthcare system, and OHIP eligibility.

ON-Marg The ON-Marg is a specialized database using census data to profile relative area-level marginalization, dependency, deprivation, ethnic concentration, and instability at various geographic levels in Ontario.

OHIP The OHIP database contains all physician billing data, including information on diagnoses and services provided, such as receipt of surgery, chemotherapy, and radiotherapy.

NACRS The NACRS collects data elements describing emergency health services provided by emergency departments in Ontario, including diagnoses, procedures, and administrative information such as wait times.

Abbreviations: ALR, Activity Level Reporting; NACRS, National Ambulatory Care Reporting System; OCR, Ontario Cancer Registry; OHIP, Ontario Health Insurance Plan; ON-Marg, Ontario Marginalization Index; RCC, regional cancer center; RPDB, Registered Persons Database. 


\section{eAppendix 1. Details of Statistical Analyses}

Continuous variables were reported with medians and interquartile ranges, and categorical variables were reported with absolute numbers and proportions. Comparison testing was performed using Kruskal-Wallis and chi-square tests, as appropriate. Median survival was estimated with Kaplan-Meier methods. Modified Poisson regression with robust error variance was used to estimate the risk of medical oncology consultation and receipt of cancer-directed therapy, and Cox proportional hazards regression was used to estimate the risk of death. The following covariates were included in the adjusted models: age (categorical), sex, year of diagnosis (2004-2010 vs 2011-2017), comorbidity burden (dichotomous), and material deprivation quintile. Data on material deprivation were missing in $0.9 \%$ of the cohort. We used a complete case analysis approach for the geographic and multivariable analyses, whereby cases with missing data were excluded. Results were reported as adjusted relative risk or hazard ratio with $95 \%$ confidence interval. 